\title{
Biochemical and Pathological Features of Postmortem Time Interval of Natural Brain Death Induced in Albino
}

\section{Rats}

\section{Elalfy MM1*, Ragheb HR ${ }^{1}$, Hamed MF² and Sleem FR ${ }^{1}$ \\ ${ }^{1}$ Department of Forensic Medicine and Toxicology, Mansoura University, Egypt ${ }^{2}$ Department pathology, Mansoura University, Egypt}

*Corresponding author: Mahmoud Elalfy, Department of Forensic Medicine and Toxicology, faculty of veterinary medicine, Mansoura University, 60-Elgomhouria St., Mansoura City, Egypt, Email: mahmoudelalfy@mans.edu

\section{Research Article}

Volume 2 Issue 5

Received Date: October 01, 2019

Published Date: October 16, 2019

DOI: $10.23880 /$ izab-16000180

\section{Abstract}

Previously we studied certain biochemical markers of postmortem time interval (PMI) in brain stem induced death in albino rats in first 30 hours after death. PMI is very important in forensic medicine for both criminal and civil conditions. We investigate histopathology, biochemical markers of enzymology and trace minerals in brain stem death model in albino rats. In the current study, we found a time dependent reduction in cholesterol and calcium level while LDH, CPK, sodium, potassium, total protein, albumin and chloride were increased as a result of tissue degradation. Notably, triglycerides are only fluctuated chemicals in blood sera suffered postmortem changes even is the highest point near 72 hours. Histopathological changes in heart, lung and brain were also time dependent except that brain suffers sever hemorrhage at the time of death onset due to increase intracranial pressure after injection of hypotonic solution in the dura mater. On conclusions, level cholesterol and trace mineral could correlate to postmortem time interval on natural induced death.

Keywords: PMI; Blood Chemistry; Trace Minerals; Natural Death; Albino Rats

\section{Introduction}

The postmortem time interval is very important significance in forensic medicine for criminal issue and civilization. The time of death can also have important implications for legal medicine such as inheritance and insurance, Even the cause of death is natural [1]. Time since death still not solved point and has interest of all 


\section{International Journal of Zoology and Animal Biology}

researchers all over the world in the field of forensic medicine.

The detection of the postmortem interval (PMI) is still one of the most challenging elements to determine and the different approaches currently used in its determination to basically lead to large post mortem windows. The combined morphological and immunohistochemically analysis could provide detailed knowledge on tissue organization and degradation after death [2]. Previously, we reported that certain biochemical could be postmortem time dependent until 30 hours after natural death induced in albino rats as well as Donaldson and Lamont recorded the biochemistry alteration after Death in brain stem death induced in rats $[3,4]$.

The body after death affected by intrinsic and extrinsic factors that could modulate postmortem time interval based on the biochemistry of vitreous humor and made complicity to find a formula for measurement PMI except in one case of including different factors like age, temperature and body weight [5].

For the evaluation of changes due to postmortem intervals based on biochemistry, none of the biochemical markers except for triglyceride which showed significant changes up to three days after death [6]. Notably serum lactate dehydrogenase increased significantly and time dependent with postmortem time interval [3]. Groups of biochemical markers in blood, bone marrow, vitreous humor, and tissues can be helpful for determination of PMI of time dependent manner. Also, losses of DNA integrity and quality have a vital role in PMI determination except certain conditions which delay or replace the putrefaction [7].

Our aim was to investigate variable blood markers and their usefulness in the forensic Diagnosis of PMI. We evaluate how biochemical parameters of the blood, suffered postmortem changes could be helpful for detection of PMI in experimental models of natural death.

\section{Material and Methods}

Animal procedures were conducted with the accordance of the animal care committee of the ethics Board of the faculty of veterinary medicine Mansoura University, Egypt.

24 male Albino rats (weight, 150-200g) were purchased from faculty of pharmacy, Mansoura
University, Egypt). They were maintained on a 12-h light/dark cycle with free access to food and water. Brain stem death was induced according to Zhang, et al. [8]. Dead rat was kept in fixed supine position on research lab. Temperature for 72 hours after induction of death. The rest of dead animals were discarded according biosafety procedure.

Blood samples of each 4 rat for each time point were collected from the heart and great vessels at autopsy at different time points after induction of death and kept for suffering postmortem changes [6]. Samples were centrifuged immediately for $20 \mathrm{~min}$ at $2000 \mathrm{RPM}$. Serum samples were stored at $-20 \mathrm{c}$ in deep freezer until measurement.

\section{Biochemical Assessment}

Sera suffered postmortem changes were tested for LDH, CPK, calcium, sodium, potassium, chloride, total protein, albumin, cholesterol and triglycerides [9-18].

\section{Histopathology Examination}

The male rats were anesthetized by thiopental and natural death was induced. Their tissues like heart, lung, and brain were separated at different time point after death and fixed in 10\% neutral buffered formalin. Fixed tissues were procedures were described previously before in details for eosin and hematoxylin staining [19].

\section{Statistical Analysis}

Statistical analysis was carried out using the one-way annova and student's t-test. $\mathrm{P}<0.05$ was considered significant [20].

\section{Results}

\section{Biochemical Markers of Postmortem Time Interval}

Notably, there was a significant increase in the level of $\mathrm{LDH}$ while CPK, albumin, total protein, sodium and chloride levels were increased with time dependent after death and correlate with cellular death. Also, cholesterol and calcium were reduced significantly at different times after death. Also, triglycerides had variable up and down levels with different time point since natural death was induced even was recorded at the highest level at 72 hours after death (Figure 1). 

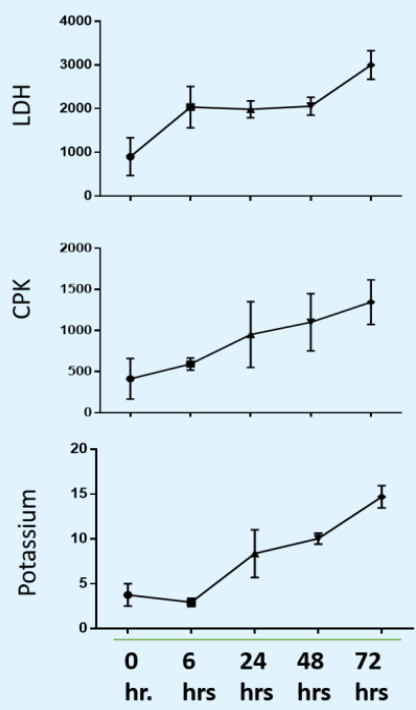

Figure 1: Show 3 groups of biochemical markers; $1 \mathrm{LDH}, \mathrm{CPK}$ and potassium were time dependent increase since time elapsed after death, $2^{\text {nd }}$ fluctuated biochemical markers and third one as cholesterol and calcium levels decreased after $6 \mathrm{hrs}$ of induced natural death.

\section{Histopathology}

In natural death induced by brain stem death show notable sever hemorrhage in the brain due to increased intracranial pressure after injection of hypotonic solution in diameter space, heart was showing the death of cardiomyocytes and slight increases in the interstitial spaces and lung displayed pulmonary atelectasis and over distended alveoli with air with death pneumocytes with the proliferation of interstitial tissue.

At 6 hours after death, brain was showing postmortem changes represented by the death of neurons and hemorrhage in the brain parenchyma, heart is showing focal death of cardiomyocytes and slight increases in the interstitial spaces and lung displays pulmonary alveoli is slit like with proliferation and death of interstitial cells.

At 24 hours after death, brain was showing postmortem changes represented by the death of neurons and severe vacillation in the brain parenchyma, heart is showing the death of cardiomyocytes and severe increasing in the interstitial spaces and lung displayed death of pulmonary alveoli is slit like and hemorrhage with proliferation and death of interstitial cells

At 48 hours after death, Brain was showing postmortem changes represented by the death of neurons and death of endothelial cell of blood capillaries, Heart is showing the death of cardiomyocytes and increasing in the interstitial spaces and Lung displays death of pulmonary alveoli and hemorrhage with proliferation and death of interstitial cells

At 72 hours after death, brain was showing postmortem changes represented by the death of neurons and vacuolation of brain parenchyma, heart is showing the death of cardiomyocytes and increasing in the interstitial spaces and lung displayed death of pulmonary alveoli and hemorrhage and death of interstitial cells (Figure 2). 


\section{International Journal of Zoology and Animal Biology}

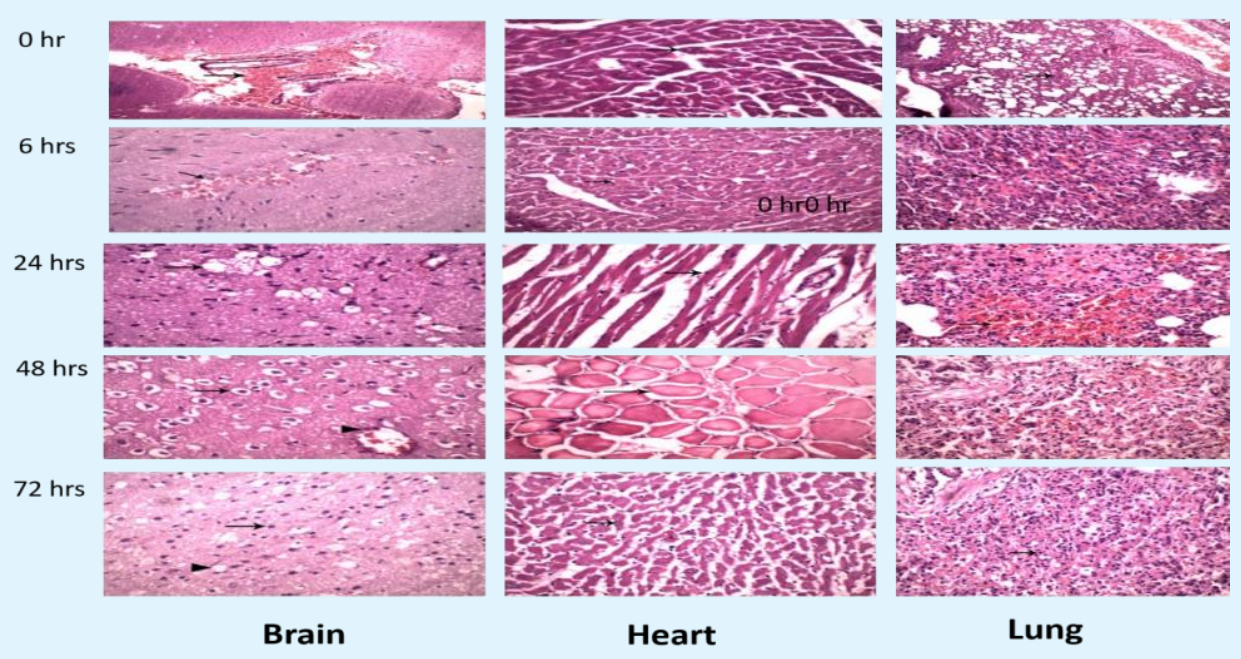

Figure 2: Show postmortem characteristic features of brain stem death and its relation to times elapsed since death in brain, heart, and lung.

\section{Discussion}

The study of PMI still interesting point of research in forensic medicine to discover a key solution in crime or in civil conditions. Previously [3], we found that a group of biomarkers could be a characteristic feature of a certain point of time after induction of death in experimental animals that mimic or quite like what happen in human corpse after deaths. The rationale of our study to investigate other markers of PMI in brain stem induced death in albino rats. The most prominent biochemical markers in blood suffer postmortem changes was a reduction in the level of cholesterol and calcium level.

The total cholesterol levels in postmortem serum samples were lower than those in ante-mortem specimens, whereas triglyceride levels in postmortem serum samples were higher than those in ante-mortem samples [21,22]. Similar studies found in human corpse of dead cases [6-23]. The other theory of microbes that have increased the population after death could have a role in lipid consuming for growth and decline in cholesterol level in the absence of immune defense of the body [24]. The fluctuations happen in the plasma triglyceride could be possible within $24 \mathrm{~h}$ after death [25].

The classical morphology still a core procedure to investigate the cause of death and postmortem changes which described in detail the pathology [26,27]. Brain death could be understood as the ultimate clinical expression of irreversible neurological stoppage, identified by irreversible coma, ablation of brainstem reflexes, and apnea [28]. The pathological feature of PMI studied before in brain stem death and start with hemorrhage and different stages of analysis in the brain, ischemic neuronal changes and focal necrosis of the brainstem [29]. The other accepted theory of brain stem death could be explained as respiratory and cardiac stoppage evidence of changes and death of myocardiocytes, peumocytes and interstitial cells [29]. Only in one case of ischemia and anoxia were sustained enough to induce an irreversible destruction of the brain and brain death enhanced stoppage of heart and lung physiology and immediately start of postmortem changes in these organs

On conclusions, blood lipid profiles and trace mineral biochemistry could share in the PMI determination in a time dependent manner in natural induced model of death. Moreover, histopathology still occupies a key for detection of time elapsed since death.

\section{Future Highlight}

Postmortem time interval will still not state of fact except in natural type of death as biochemical markers differ according many events occur at time of death, before and based on causes of death as we found earlier that biochemicals differ in freshwater or saltwater drowning [30]. 


\section{International Journal of Zoology and Animal Biology}

All authors have no conflict of interest

\section{References}

1. Henssge CB, Madea B, Knight L, Nokes, Krompecher T (1995) The Estimation of the Time Since Death in the Early Postmortem Period, Arnold, London.

2. Mazzotti MC, Fais P, Palazzo C, Fersini F, Ruggeri A, et al. (2019) Determining the time of death by morphological and immunohistochemical evaluation of collagen fibers in postmortem gingival tissues. Leg Med (Tokyo) (39): 1-8.

3. Elalfy MM, El Hadidy G, Mona (2018) Biochemical Identifiers of Postmortem Time Interval on Autopsy of Albino Rats versus Physiological One. Global Journal of Medical Research: G-Veterinary Science and Veterinary Medicine 18(1): 9-12.

4. Donaldson AE, Lamont IL (2013) Biochemistry Changes That Occur after Death: Potential Markers for Determining Post-Mortem Interval. PLoS ONE 8(11): e82011.

5. Cordeiro C, Ordonez Mayan L, Lendoiro E, Febrero Bande M, Vieira DN, et al. (2019) A reliable method for estimating the postmortem interval from the biochemistry of the vitreous humor, temperature and body weight. Forensic Sci Int 295: 157-168.

6. Uemura K, Shintani Ishida K, Saka K, Nakajima M, Ikegaya $\mathrm{H}$, et al. (2008) Biochemical blood markers and sampling sites in forensic autopsy. J Forensic Leg Med 15(5): 312-317.

7. Ragheb HH, Elalfy MM, Ali FR (2019) Biochemicals and DNA degradation identifier markers of postmortem time interval in different causes of death. Vet Open A Open J 1(1): 1-11.

8. Zhang S, Cao S, Wang T, Yan B, Lu Y, et al. (2014) Modified brain death model for rats. Exp Clin Transplant 12(5): 469-473.

9. Assault A (1983) Lactate dehydrogenase. UV-method with pyruvate and NADH. In: Bergmeyer HU, Bergmeyer J, Grassl M, et al. (Eds.), Methods of Enzymatic Analysis. III. Enzymes 1: Oxidoreductases, Transferases, 3rd (Edn.), Verlag-Chemie, Weinheim pp: 118-126.
10. Tietz NW (1976) Fundamentals of clinical chemistry. Cpk, W.B. Saunders Co., Philadelphia pp: 940-941.

11. Barnett RN, Skodon SB, Goldberg MH (1973) Performance of "kits" used for clinical chemical analysis of calcium in serum. Am J Clin Pathol 59(6): 836-845.

12. Tietz NW (1976a) Fundamentals of clinical chemistry, chloride, W.B Saunders, Philadephia pp: 897.

13. Tietz NW (1976b) Fundamentals of clinical chemistry, potassium, W.B Saunders, Philadephia pp: 874.

14. Tietz NW (1983) Clinical guide to laboratory tests, sodium, W.B Saunders, Philadephia pp: 384.

15. Yatzidis HL (1987) A colorimetric method for detection of total protein. J Clinical Chemistry Journal 23: 908.

16. Dumas BT, Watson WA, Biggs HG (1971) Albumin standards and the measurement of serum albumin with bromcresol green. Clin Chim Acta 31(1): 87-96.

17. Naito HK, Kaplan A (1984) A colorimetric method for determination of Cholesterol. Princeton, Clin Chem the CV Mosby CO. St Louis, Toronto pp: 1194-11206.

18. Fassati P, Prencipe L (1982) Serum tiglycerides determined colorimeeic with an enzyme that produce hydrogen peroxide. Clin Chem 28 (10): 2077-2080.

19. Bancroft JD, Gamble M (2002) Theory and practice of histological techniques. $5^{\text {th }}$ (Edn.), Philadelphia Churchill Livingstone.

20. Snedecor, George W, Cochran William G (1989) Statistical Methods, $8^{\text {th }}$ (Edn.), Iowa State University Press, USA.

21. Hart AP, Zumwalt RE, Dasgupta A (1997) Postmortem lipid levels for the analysis of risk factors of sudden death: usefulness of the Ektachem and Monarch analyzers. Am J Forensic Med Pathol 18(4): 354-359.

22. Girard C, Scarpelli MP, Tettamanti C, Palmiere C (2017) Postmortem evaluation of cholesterol, triglyceride, and apolipoprotein levels. Int J Legal Med 131(6): 1777-1782.

23. Guillermo OAJ, Mildrey M, Isabella EJ, Lorena JB, Fabian SOM, et al. (2013) Early atherosclerotic 
lesions and post-mortem serum cholesterol level in a group of Colombian children Inicio Archivos 33(3).

24. Wood PL, Shirley NR (2013) Lipidomics Analysis of Postmortem Interval: Preliminary Evaluation of Human Skeletal Muscle Metabolomics 3(3): 127.

25. Sarkioja T, Yla Herttuala S, Solakivi T, Nikkari T, Hirvonen J (1988) Stability of plasma total cholesterol, triglycerides, and apolipoproteins B and A-I during the early postmortem period. J Forensic Sci 33(6): 1432-1438.

26. Saukko P, Knight B (2004) The forensic autopsy, in: Saukko P, Knight B, et al. (Eds.), Knight's Forensic Pathology, $3^{\text {rd }}$ (Edn.), Hodder Arnold, London pp: 151.

27. Maeda $\mathrm{H}, \mathrm{Zhu} \mathrm{BL}$, Ishikawa $\mathrm{T}$, Quan $\mathrm{L}$, Michiue $\mathrm{T}$ (2009) Significance of postmortem biochemistry in determining the cause of death. Leg Med (Tokyo) 11(S1): 46-49.

28. Machado C (2010) Diagnosis of brain death. Neurol Int 212(1): e2.

29. Matakas F, Cervos Navarro J, Schneider H (1973) Experimental brain death Morphology and fine structure of the brain. Journal of Neurology Neurosurgery and Psychiatry 36(4): 497-508.

30. Elalfy MM, Ragheb HH, Hamed MF, Sleem FR (2019) Biochemical Markers and Pathological Features of Postmortem Time Interval Distinguishing Freshwater and Saltwater Drowning Induced Death in Albino Rats. Biomed J Sci \& Tech Res 20(1): 14713-14720. 